\title{
Interpretation of geoelectric surveys using synthetic models and its application for study of groundwater resources in semiarid regions of Minas Gerais, Brazil
}

\author{
Jorge L. S. Gomes ${ }^{1,2}$, Valiya M. Hamza ${ }^{1}$ and Fabio P. Vieira ${ }^{1},{ }^{1}$ Observatório Nacional - ON and ${ }^{2}$ UFVJM.
}

\section{Copyright 2019, SBGf - Sociedade Brasileira de Geofísica}

This paper was prepared for presentation during the $16^{\text {th }}$ International Congress of the Brazilian Geophysical Society held in Rio de Janeiro, Brazil, 19-22 August 2019.

Contents of this paper were reviewed by the Technical Committee of the $16^{\text {th }}$ International Congress of the Brazilian Geophysical Society and do not necessarily represent any position of the SBGf, its officers or members. Electronic reproduction or storage of any part of this paper for commercial purposes without the written consent of the Brazilian Geophysical Society is prohibited.

\section{Abstract}

Synthetic models of subsurface fracture systems have been employed for interpretation of electrical resistivity surveys. The purpose has been identification of seepage zones of meteoric waters through fracture systems in the basement rock. The study was carried out along fourteen profiles transverse to the bed of the intermittent stream Bolas, near the locality of Martins (Jenipapo de Minas, $M G$ ). The results obtained have allowed characterization of contrasts in electrical properties at fifteen sites and identification of seepage zones at depths varying from 2 to 20 meters. Results of numerical simulations have been useful in mapping seepage zones, essential for design of subsurface dam systems.

\section{Introduction}

Recent of progress in geoelectric instrumentation and advances in affiliated software have opened up possibilities for prompt analysis of field observations, visual display of subsoil structures by inversion techniques and numerical simulations of field data as a valuable aid geophysical prospection.

In general, synthetic models in geophysics are used in the pre-survey stages to test the possibility of using a particular geophysical method in fieldwork or testing new processing methods and filters. In geoelectrical surveys synthetic models are employed for verifying the best response of a given geological environment. This is useful in selection of the best method, array and electrode spacing that will be in field survey. However, the advantages in development of synthetic models for correlation and interpretation of results of geoelectric profiles are not commonly explored.

In the present work we report progress obtained in the use of numerical simulations of electrical resistivity data acquired in field survey along a stream bed, located in the municipality of Jenipapo de Minas, in the semiarid region of southeast Brazil (Figure 1). We also compare results of simulations with the geoelectric profiles derived from the inversion process of field data. The main objective of this work is to investigate the nature of geoelectric fields generated by near surface seepage flows of meteoric waters. In this process we also examine a consistent and robust interpretation of results that allows more reliable evaluation of the geoelectrical response along the profiles surveyed.

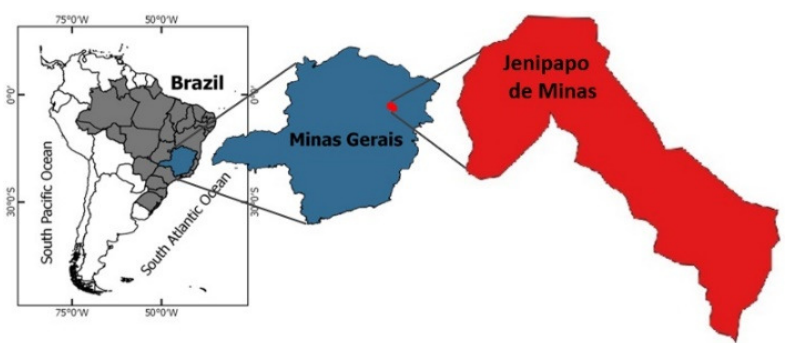

Figure 1 - Location of study area (Jenipapo de Minas).

\section{Geological aspect}

The geological characteristics of the municipality of Jenipapo de Minas is determined almost predominantly by the Salinas formation (pEms) of the Macaúbas group. In the east, according to CODEMIG (2012), there are areas of Cenozoic cover (QTd), composed of eluvio-colluvionar and restricted alluvial deposits on tertiary plateau surfaces. Figure 2 illustrates the area extent of local geologic features. Also illustrated in this map are the limits of the hydrographic basin of the stream Bolas (black bold curve) and the associated drainage systems (blue curves) of the study area. The triangle (in yellow color) indicates the outlet point of the drainage system. The red circle points to the site of the geoelectric surveys.

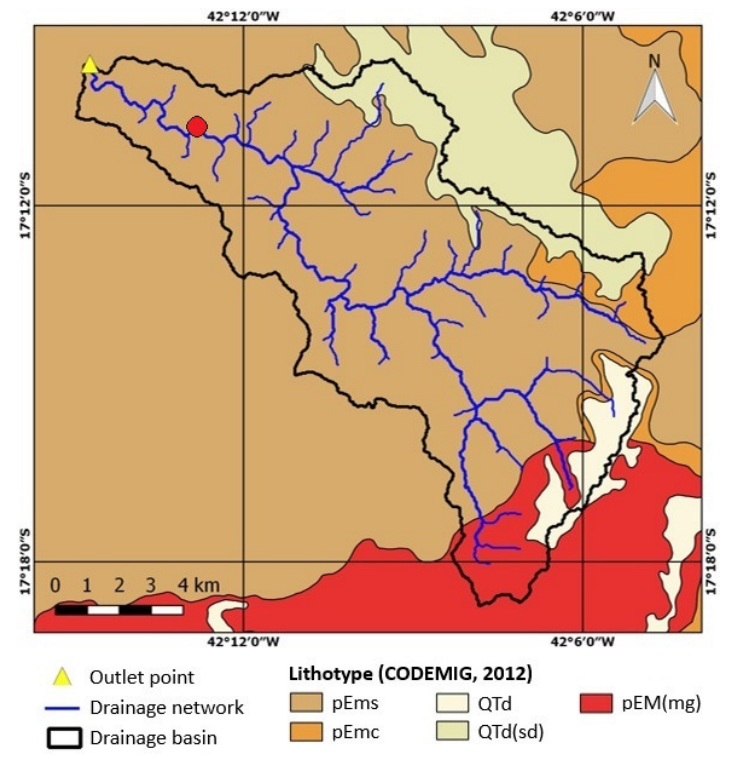

Figure 2 - Map of local geologic lithotypes and drainage network in the region of the stream Bolas. 


\section{Hydrogeological characteristics}

The groundwater systems in the municipality of Jenipapo de Minas are composed of two hydrogeological domains: 1) highly fractured rock formations of Neoproterozoic metamorphic rocks and Paleozoic granites, 2) Cenozoic detrital covers, which are highly permeable for groundwater flows. As a result, the aquifers in these domains can be considered as falling into the categories of near impermeable fractured systems and highly permeable granular systems. The hydrogeological potential of the fissure system is dependent on the intercommunication of the discontinuities, an aspect that usually translates to random and small-scale reservoirs (CPRM, 2005). It occurs throughout the municipality and is related to the schist rocks of the Macaúbas Group and the Mangabeiras granite. In general, it presents low hydrogeological potential, with structural features responsible for local variations in productivity. The granular aquifer system is represented by poorly consolidated sediments, which constitute the detrital deposits of sand-clay composition. In hydrogeological terms, it may be considered as lateralized. These have primary porosity and good permeability (CPRM, 2005; GOMES ET AL, 2016).

The rock types found in the study area in Figure (2) are predominantly schists, outcrops of which can be found along the intermittent stream Bolas. It has a generally undulating topography with flat terrain along some part of the stream and also in the plateaus. This stream has none surface runoff (water flow) during the dry season.

The presence of cleavage, schistosity, fractures and faults can affect the groundwater recharge by increasing or decreasing the seepage rate. However, the rocks themselves are relatively impermeable and would yield little water in their unaltered state. Hence, improved understandings of the interactions between surface and the fractured groundwater system is of particular importance in the study area.

The Bolas stream is a tributary of the perennial Setubal River. Ground water is also available from alluvium valleys such as Bolas basin that can impound water by using of underground dams since there are impermeable bedrocks along the streams.

Several locations in the Jenipapo de Minas have potential as sources of groundwater supplies. Studies carried out by CPRM (2005) are based on lithologic sequences encountered in 25 wells located on this schist domain. All of them are located in Macaúbas group. The water flow varies from 1.8 to $31.68 \mathrm{~m}^{3} / \mathrm{h}$ in these wells.

\section{Geophysical Studies}

A number of field studies were carried out in the municipality of Jenipapo de Minas. The focus of earlier efforts has been in mapping intermittent streams and identifying suitable sites for detailed geophysical surveys. In the present work, we report progress obtained in electrical resistivity surveys in the locality of Martins. The selected site for the geoelectric profiles survey is a segment of the local intermittent stream Bolas. The locations of the geoelectric profiles are indicated in Figure
3 as red and yellow stripes. The red lines indicate the four transversal profiles and the yellow line the control profile surveyed in the left bank of the stream Bolas. The course of intermittent water flow in the stream is indicated by blue dashed curve. The geoelectric surveys were carried out in 2017 and 2018.

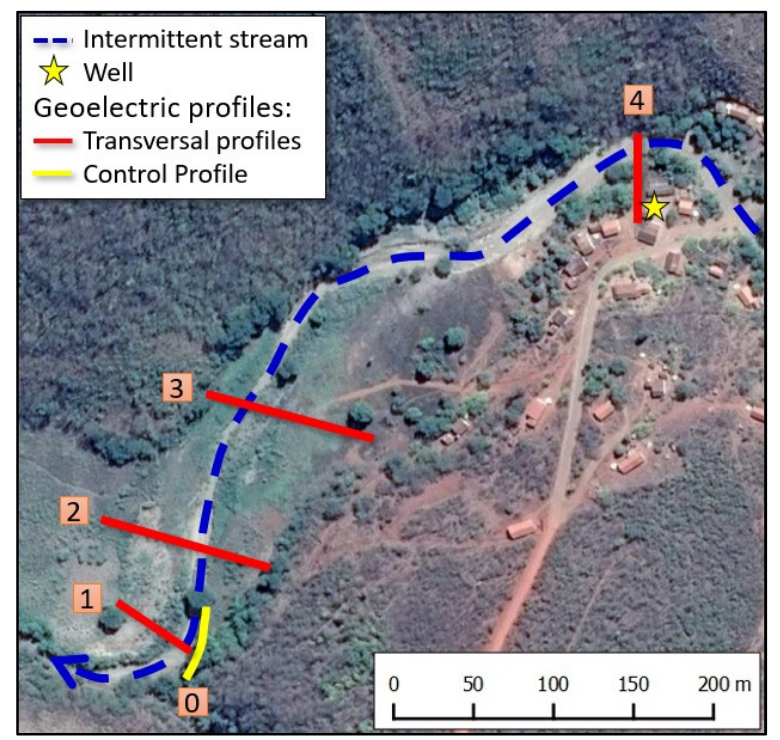

Figure 3 - Map of the study area indicating the course of the stream bed near the village of Martins and the locations of geoelectric profiles.

\section{Method}

The methodology adopted in the present work is based on procedures described in practices described in the literature of applied geophysics (DOBRIN \& SAVIT, 1988; TELFORD et al., 1990; VOGELSANG, 1995; KEAREY et al., 2002; MILSOM, 2003; KIRSCH, 2009). In general, geoelectrical methods have a particularity in relation to other geophysical techniques. It encompasses several field techniques and a large number of experimental arrangements. Consequently, field procedures can be adapted according to the characteristics of the area and the target to be studied. However, there are highlights within this vast methodology that should be prioritized in relation to others. It should be noted that recent advances in the geoelectric methods present an evolution in data acquisition and processing, both in the instrumental part and in software development. This has made the field data processing more accurate and reliable (BRAGA, 2016).

During the initial phase, the data acquired in the field were processed using the AGI Earth Imager 2D Software. Finite element techniques (COGGON 1971; RIJO 1977; DEY AND MORRISON 1979) were employed in data processing and in elaboration of electric resistivity models of the study area. Cholesky decomposition technique was adopted in solving the model equations. The main purpose has been to reduce the misfit between field measurements and calculated values, within the framework of a physically plausible model. 
The inversion method employed in processing field data is based on the procedure proposed by Loke et al (2003). One of the objectives of the inversion scheme is to find a resistivity model whose response (predicted values) provide best fits to the measured data. Examples of the goodness of fit characterized by calculating root mean square (RMS) error are given in Table 1.

Table 1 - Profile identification, electrode array and root mean square (RMS) values of electrical resistivity data.

\begin{tabular}{|c|c|c|}
\hline Profile & Array & RMS $\%$ \\
\hline 0 (control) & Dipole-Dipole & 3,13 \\
\hline 1 & Dipole-Dipole & 2,46 \\
\hline 2 & Dipole-Dipole & 2,95 \\
\hline 3 & Dipole-Dipole & 2,03 \\
\hline 4 & Dipole-Dipole & 2,94 \\
\hline
\end{tabular}

The geological correlation of geoelectric survey results was established on the basis of data from the lithological log of the well at Martins (in the study area) and the range of electrical resistivity found in the literature (Table 2).

Table 2 - The electrical resistivity range (in $\Omega \mathrm{m}$ ).

\begin{tabular}{|c|c|c|c|c|}
\cline { 2 - 5 } \multicolumn{1}{c|}{} & Clay & $\begin{array}{c}\text { Gravel and } \\
\text { sand }\end{array}$ & Schists & Sands \\
\hline Sharma, 1997 & $5-100$ & $700-10^{\wedge} 4$ & & \\
\hline Vogelsang, 1995 & $3-150$ & $200-5000$ & & \\
\hline Mareš et al., 1984 & $10-100$ & & $100-10^{\wedge} 4$ & $10^{\wedge} 2-10^{\wedge} 4$ \\
\hline Telford et al., 1990 & $1-100$ & & $20-10^{\wedge} 4$ & \\
\hline Range adopted & $\mathbf{5 - 1 5 0}$ & $\mathbf{2 0 0 - 1 0 \wedge 4}$ & $\mathbf{2 0 - 1 0 \wedge 4}$ & $\mathbf{1 5 0 - 1 0 \wedge 4}$ \\
\hline
\end{tabular}

The observational features of the control profile served to better delineate the resistivity range. Its compatibility was tested with synthetic models. Thus, the models created provide a better interpretation of field results. It also reduces uncertainties in data analysis and avoid eventual effects of spurious artifacts.

\section{Results}

The results reported in the present work is continuation of the earlier efforts, parts of which has been published in several previous works (GOMES et al, 2016; 2017; 2018). The focus here is on presenting new results obtained in the use of synthetic models of electrical resistivity in validating the interpretations of the profiles considered in the earlier works.

Starting from the control profile (labeled as 0) it was possible to make reinterpretations of correlations between lithologic units of near surface layers and resistivity profile sections. Such results have served as the local reference standard for association of geoelectrical response with the lithologic units. The survey was carried out for the natural outcrop on the left bank of the stream Bolas. This profile is illustrated in Figure 4. The upper panel $(A)$ of this figure refers to wide angle photo of the left bank showing a sedimentary layer of clay overlying the outcrop of local basement rock. The second panel (B) illustrates the result of resistivity survey along this profile, obtained in the inversion process. The third panel $(\mathrm{C})$ is the synthetic model based on resistivity values adopted. The lower panel (D) of this figure refers to result of numerical simulation of the electrical resistivity model. The values obtained in this procedure are in general agreement with the expected resistivity ranges for schists (20 to $10^{4} \Omega \mathrm{m}$ ) and for clays (5 to $150 \Omega \mathrm{m}$ ), mentioned the in applied geophysics literature.
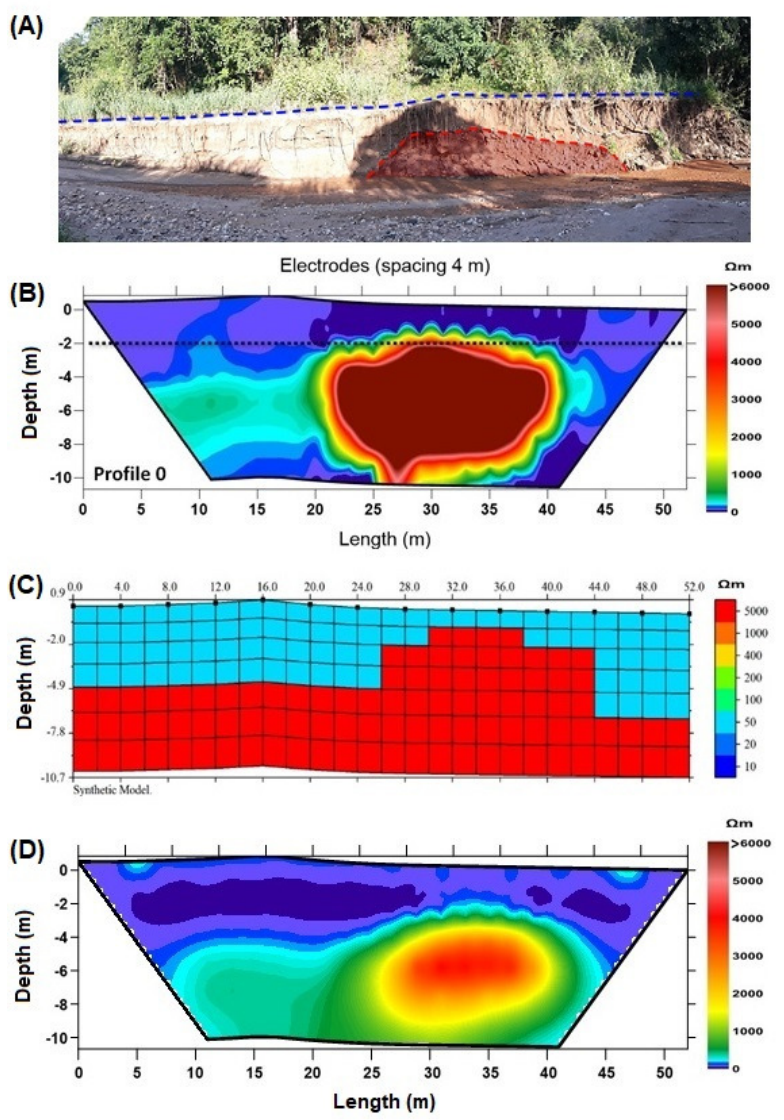

Figure 4 - Control profile. The location of geophysical field survey $(A)$, geoelectric survey result $(B)$, synthetic model (C) and the result of the model simulation (D).

Similar results obtained in other geoelectric profiles and their respective synthetic models are illustrated from Figure 5 to Figure 8. in these illustrations the upper panel represent the geoelectric survey result, the middle panel the synthetic model and the lower panel the result of the model simulation. The black arrows in these illustrations indicate the approximate limits of the main channel of the stream. The right margin is indicated by the abbreviation $\mathrm{RM}$ and the left margin by the abbreviation LM.

The geoelectric profile 1 (Figure 5) reveals the presence of a long narrow zone of low resistivity that start from the main stream area dip to the right margin in depth. These are considered as inclined permeable zones that allow seepage. Note that the geoelectric model has been possible to reproduce the observed electrical resistivity pattern.

In the geoelectric profile 2 (Figure 6) it was possible to identify two regions of low resistivity in the basement rock. The first starts from the main stream area dipping to the right margin in depth, this one is considered as inclined permeable zone. The second anomaly looks linked to flows 
incoming by the left flank groundwater since it has a more horizontal shape and don't connected with the main stream. The synthetic model result also corroborates with these anomalies interpretation.
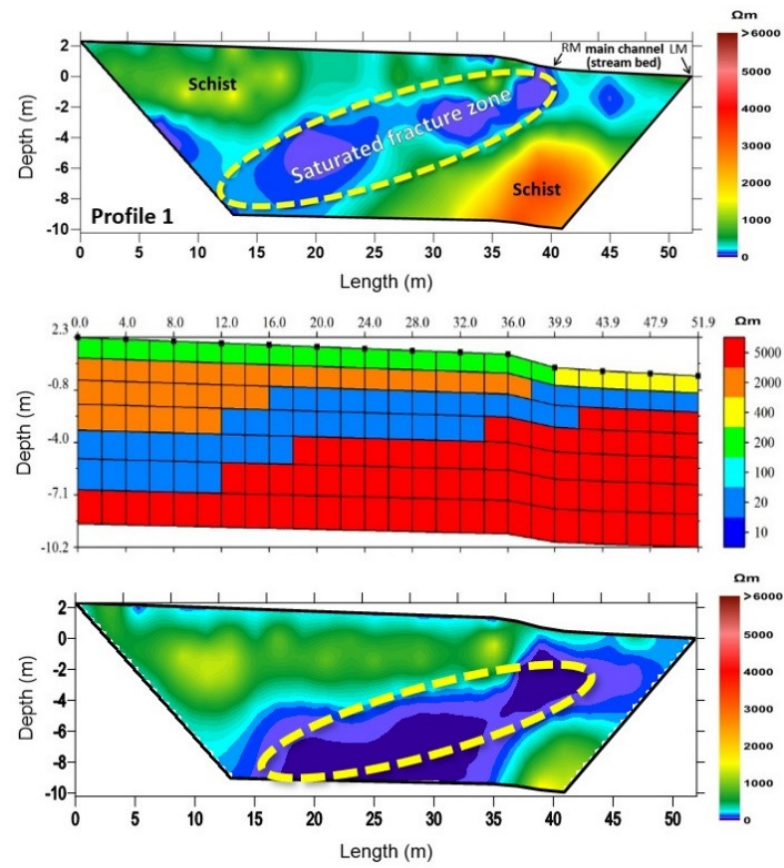

Figure 5 - The results of geoelectric profile 1 showing a narrow zone of low resistivity in the basement rock.
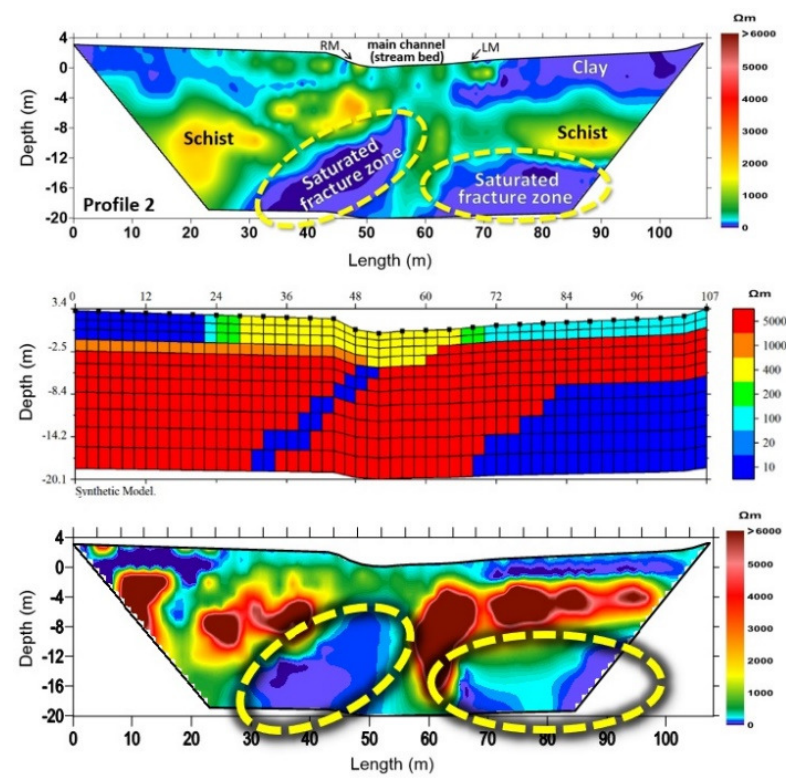

Figure 6 - The results of geoelectric profile 2 that show a fault (on the stream bedrock) and the fracture zone (left margin).

The geoelectric profile 3 (Figure 7) also reveals two anomalies of low resistivity in the basement rock. Both extend form surface soil layer along the banks and reaches the deeper parts of the profile. The ambiguity of electrical resistivity does not allow inferences as to the contact between the sedimentary layer and the bedrock. However, it can be inferred (with some uncertainty) in the results of the synthetic model.
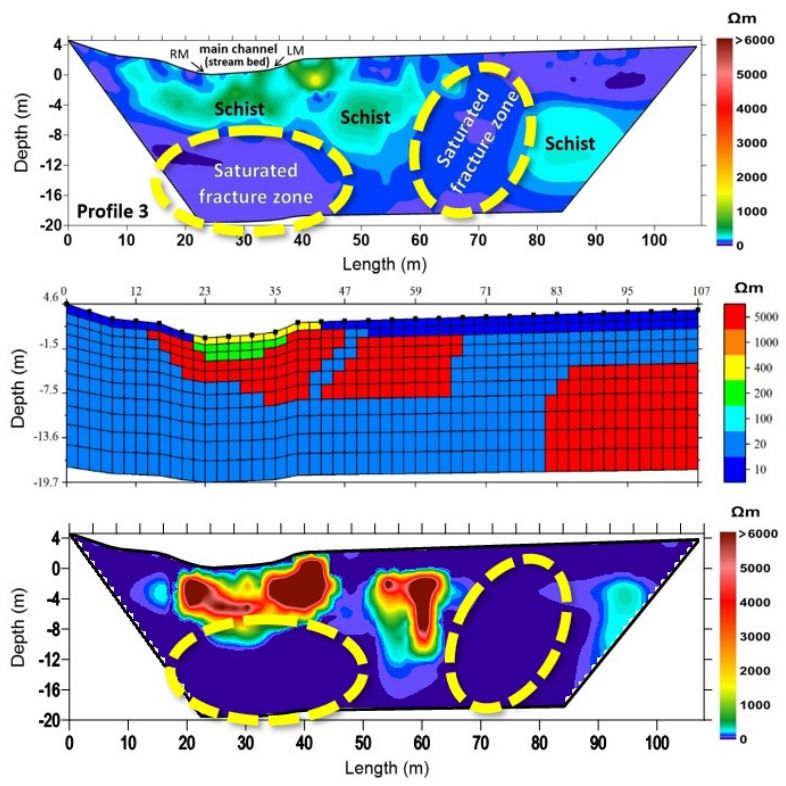

Figure 7 - The results of geoelectric profile 3 illustrating a complex fractured zone along the profile.

The geoelectric profile 4 (Figure 8) identified the presence of an upper layer of low resistivity $(<100 \Omega \mathrm{m})$ along the left margin of the profile, where soils rich in clay materials are present. At deeper levels the resistivity starts to increase and match with the description of well log. Along the main channel the resistivity values are in excess of $500 \Omega \mathrm{m}$. It is possible that the bedrock is not fractured in the stream bed.
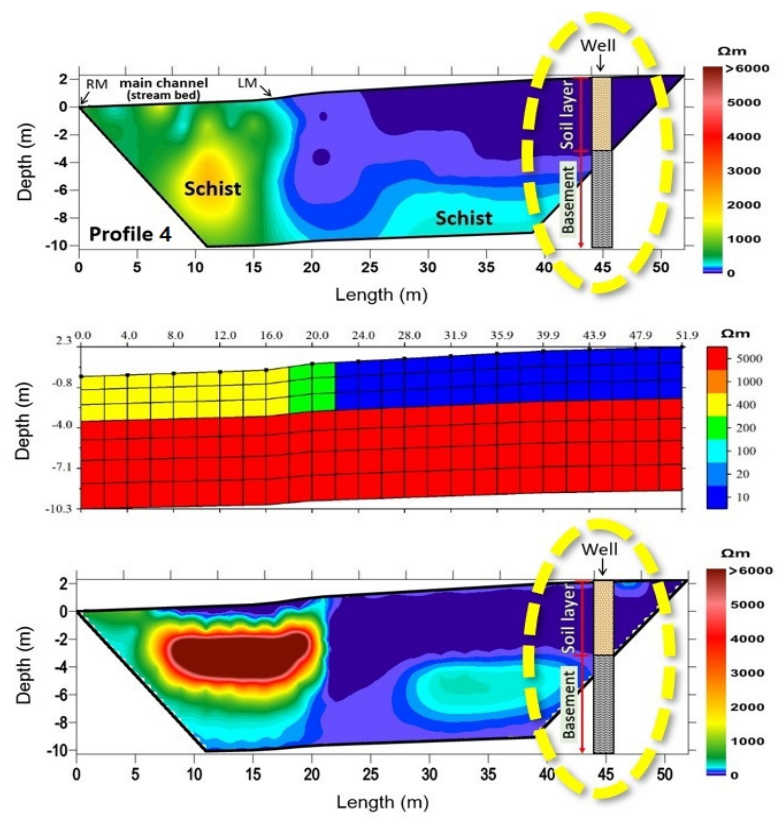

Figure 8 - The results of profile 4 in association with the lithologic well log profile. 


\section{Conclusions}

The results of geoelectric surveys indicate the existence of two layers. The first is a sedimentary layer composed of alluvium sediments (with predominance of sand) on the stream bed and rich in clay along the margins. Underlaying it is a second layer that was identified as schists of the basement complex. This information was verified in the well log, as also in the geologic map of the study area.

Anomalies in the basement rock were identified in the resistivity profiles 1,2 and 3 , It indicates that basement layer is highly fractured, contributing thereby to recharge of fissural aquifer. The synthetic model results have corroborated with the identification and location of the faults and fracture zones in the basement complex.

Water resources that can be extracted at a given location depend, therefore, on the volume of fragmented or fractured rocks present in the subsurface at that location. The meteoric water probably migrates down along inclined slope of the fractures and also along sedimentary layers toward the center of the drainage network and also by seepage along the stream beds. Finally, it merges with groundwater moving into aquifer through fractures in the schist rock.

In view of these results the synthetic models should be considered as useful in constraining the uncertainty in interpretation of field profiles. The results are of considerable help in studies of geological correlation and interpretation of the geoelectric surveys.

\section{Acknowledgments}

This study is part of the doctoral thesis project of the first author at the Department of Geophysics of the National Observatory - ON/MCTIC. The field surveys were carried out with operational support by the Municipality of Jenipapo de Minas and the Group of Studies and Research in Geosciences and Engineering of the Jequitinhonha and Mucuri Valleys - GEOVALES and the Foundation for Support of Scientific Research of the State of Rio de Janeiro - FAPERJ. The second author is recipient of a scholarship granted by Brazilian National Research Council - CNPq (Process No. 306755/2017-3).

\section{References}

BRAGA, A. C. O. Geofísica aplicada: métodos geoelétricos em hidrogeologia. Oficina de Textos, São Paulo. 2016.

CODEMIG - Companhia de Desenvolvimento Econômico de Minas Gerais. Mapa Geológico da folha Jenipapo, Minas Gerais, Brasil. Folha SE.23-X-D-III. 2012.

COGGON, J. H. Electromagnetic and electrical modeling by the finite element method. Geophysics, v. 36, p. 132155. 1971.

CPRM - Companhia de Pesquisa de Recursos Minerais. Diagnóstico do município de Jenipapo de Minas, MG. Projeto Cadastro de Abastecimento por Águas Subterrâneas, Vale do Jequitinhonha. 2005.
DEY. A., MORRISON, H. F. Resistivity modelling for arbitrarily shaped two - dimensional structures. Geophysical Prospecting, v. 27, p. 106-136. 1979.

DOBRIN, M., SAVIT, C. H. Introduction to geophysical prospecting. 4ed. McGraw-Hill Book Co. 1988.

GOMES, J. L., VIEIRA, F. P., HAMZA, V. M. Sondagem elétrica vertical aplicada aos estudos para implantação de barragens subterrâneas no Município de Jenipapo de Minas. VII Simpósio Brasileiro de Geofísica da SBGf. Ouro Preto. 2016.

GOMES, J. L., VIEIRA, F. P., HAMZA, V. M. Use of geophysical surveys in selection of sites for underground dams in the municipality of Jenipapo de Minas. Congresso Internacional da Sociedade Brasileira de Geofísica - SBGf. Rio de Janeiro. 2017.

GOMES, J. L., VIEIRA, F. P., HAMZA, V. M. Use of timelapse geophysical surveys in selection of sites for underground dams in the semiarid region of southeastern Brazil. Groundwater for Sustainable Development, v.7, p. 232-238. 2018.

LOKE, M.H., ACWORTH, I., DAHLIN, T. A comparison of smooth and blocky inversion methods in 2D electrical imaging surveys. Exploration Geophysics, v. 34, p. 182187. 2003.

KEAREY, P., BROOKS, M., HILL, I. An Introduction to Geophysical Exploration. 3 ed. UK: Blackwell Publishing Company. 2002.

KIRSCH, R. Groundwater Geophysics: A Tool for Hydrogeology. 2nd. Springer-Verlag Berlin Heidelberg. 2009.

MAREŠ S., HRÁCH, S., MAREK, F., MATOLÍN, M., GRUNTORÁD, J., KAROUS, M., SKOPEC, J. Introduction to applied geophysics. D. Riedell Publishing Company of Kluwer Academic Publishers Group. Prague.1984.

MILSOM, J. The Geological Field Guide Series. 3ed. John Wiley \& Sons Ltd. 2003.

RIJO, L. Modelling of electric and electromagnetic data, Ph. D. Thesis, University of Utah. 1977.

SHARMA, P. V. Environment and engineering geophysics. Cambridge University Press. 1997.

TELFORD, W. M., GELDART, L. P., SHERIFF, R. E., KEYS, X. Applied Geophysics. 2nd. Cambridge University Press, London. 1990.

VOGELSANG, D. Environmental Geophysics: a practical guide. Springer-Verlag Berlin Heidelberg New York. 1995. 